\section{Video consulting study}

This excellent study recognises the growing interest in using video consultation with specific patient cohorts and in specific circumstances. ${ }^{1}$ It can be a change for the good, but only if done for the right reasons. The technology needs to evolve, although there are some caveats about the experience described above. Notably, many practices are seeing the benefits of combining telephony and video traffic using the same 'pipe', avoiding the need for Wi-Fi upgrades. For others, the arrival of HSCN removes the old N3 connectivity issues. Video can now be played directly into modern browsers, reducing the need for additional downloads.

GPs should be able to switch between phone and video consultation quickly and easily, via their phone, laptop, or other mobile devices, and do so in a way that is familiar to the patient. Resultant conversations should be associated with the patient's record to inform clinical and administrative decision making. Connectivity should not be a barrier to efficient communication.

Many practices are recognising that this is not about choosing one form of communication over another; it is about choosing the right form of communication at the time. Phone, video, and face-to-face consultations can work together, if the right approach is taken.

Paul Bensley,

Director, $X$-on.

Email: paul.bensleylax-on.co.uk

\section{REFERENCE}

1. Donaghy $\mathrm{E}$, Atherton $\mathrm{H}$, Hammersley V, et al. Acceptability, benefits, and challenges of video consulting: a qualitative study in primary care. $\mathrm{Br}$ J Gen Pract 2019; DOI: https://doi.org/10.3399/ bjgp19X704141.

\section{Skill-mix change in general practice}

It is good to see exploratory research on the introduction of new roles in general practice in Manchester and we agree with the conclusion of Nelson et al that introducing new roles to general practice is not a simple process. ${ }^{1}$ However, we disagree with the assertion by the authors that Limited evidence suggests PAs may provide safe and effective care that is acceptable to patients but may also generate activity in terms of return and visits, tests, or prescriptions ordered, and referrals.

Our comparative observational study of 2086 records of patients presenting at same-day appointments in 12 general practices in England (funded by the National Institute for Health Research) published in this journal ${ }^{2}$ found that there

were no significant differences in the rates of re-consultation (rate ratio 1.24, $95 \%$ confidence interval $[\mathrm{Cl}]=0.86$ to 1.79, $P=0.25)$. There were no differences in rates of diagnostic tests ordered 11.08, $95 \% \mathrm{Cl}=0.89$ to $1.30, \mathrm{P}=0.44 \mathrm{l}$, referrals (0.95, $95 \% \mathrm{Cl}=0.63$ to $1.43, \mathrm{P}=0.80$ ), prescriptions issued $11.16,95 \% \mathrm{Cl}=0.87$ to $1.53, P=0.31$ ), or patient satisfaction (1.00, $95 \% \mathrm{Cl}=0.42$ to 2.36, $\mathrm{P}=0.99$ ). Records of initial consultations of $79.2 \%$ ( $\mathrm{n}=145$ ) of PAs and $48.3 \%$ ( $\mathrm{n}=99$ ) of GPS were judged appropriate by independent GPs (P<0.001). The adjusted average PA consultation was 5.8 minutes longer than the GP consultation $195 \% \mathrm{Cl}=2.46$ to 7.1 ; $\mathrm{P}<0.001)$; cost per consultation was GBP E6.22 (US\$10.15) lower $195 \% \mathrm{Cl}=-7.61$ to $-2.46, \mathrm{P}<0.001)$.

We concluded that the processes and outcomes of PA and GP consultations for same-day appointment patients are similar at a lower consultation cost.

\section{Vari M Drennan MBE,}

Professor of Health Care and Policy Research, Centre for Health and Social Care Research, Joint Faculty of Kingston University and St. George's University of London, London.

Email: v.drennanasgul.kingston.ac.uk

\section{REFERENCES}

1. Nelson PA, Bradley F, Martindale AM, et al. Skill-mix change in general practice: a qualitative comparison of three 'new' non-medical roles in English primary care. Br J Gen Pract 2019; DOI: https://doi.org/10.3399/bjgp19X704117.

2. Drennan VM, Halter M, Joly L, et al. Physician associates and GPs in primary care: a comparison. Br J Gen Pract 2015; DOI: https://doi.org/10.3399/ bjgp15X684877.

DOI: https://doi.org/10.3399/bjgp19X705017

\section{MUS and adverse experiences}

Delighted to see the response from Sarah Evans. ${ }^{1}$ Adverse childhood experience and relational trauma in particular are now recognised to be potent and widespread causes of MUS. As the effects are registered and maintained sub-cortically, in the limbic brain and in the lower, reptilian, brain, it should be no surprise that CBT is of limited benefit. Neuroscience has met psychotherapy in recent years and trauma-focused therapies such as Somatic Experiencing (Dr Peter Levine, https://www. seauk.org.uk, as referenced by Sarah), Sensorimotor Psychotherapy (Dr Pat Ogden, https://www.sensorimotorpsychotherapy. org), and Internal Family Systems (IFS, Dr Richard Schwartz, https://www. internalfamilysystemstraining.co.uk) are all proving to be much more effective in addressing the somatic expressions of post-psychic trauma and adversity than psychodynamic, CBT, psychoanalysis, or indeed many of the other traditional relational/attachment-oriented therapies. The body is increasingly being recognised as a seat of the unconscious and presentations are as many and varied as the body is complex. Dr Gabor Maté, GP and trauma and addiction specialist, has much useful to say on this also (https://drgabormate.com).

NHS provision of trauma assessment and management is patchy but improving. Complex PTSD has only just made it into ICD11 and is undoubtedly at the root of many MUS, but relevant services are some years down the line yet.

I would encourage all GPs to carry out a short trauma assessment interview for all their regular attenders, MUS, and heartsinks. You will be surprised at what is lurking in the past experiences of these patients, and, now that we have effective therapies, equally surprised at how quickly they respond to these new tailored interventions.

To get quickly up to speed with developments in this area I would highly recommend reading The Body Keeps the Score by Professor Bessel van der Kolk. (Penguin, 2015, ISBN 978-0141978611).

B Ephrem Bogues,

Retired GP and Psychodynamic

Psychotherapist.

Email: e.boguesdaicloud.com

\section{REFERENCE}

1. Evans SC. Medically unexplained symptoms: are 